\title{
DIÁRIO DE CAMPO: RELATOS DE VISITAS ÀS ESCOLAS PARA ALUNOS SURDOS
}

\author{
Mariana Schwantes é graduada em Letras pela Universidade do Estado do Rio de Janeiro - UERJ. \\ E-mail: marischwantes@yahoo.com.br \\ Angela Corrêa Ferreira Baalbaki é professora na Universidade do Estado do Rio de Janeiro - UERJ. \\ E-mail: angelabaalbaki@hotmail.com \\ Vanessa dos Santos Galvão Noronha é graduanda em Letras pela Universidade do Estado do Rio de Janeiro - UERJ. \\ E-mail: vanessa.santosgn@gmail.com \\ Débora Ramalho Moraes da Silva é graduanda em Letras pela Universidade do Estado do Rio de Janeiro - UERJ. \\ E-mail: deborarms@outlook.com.br \\ Vicelina Geralda de Souza Mathias é graduanda em Letras pela Universidade do Estado do Rio de Janeiro - UERJ. \\ E-mail: vicelinamathias@gmail.com
}

\section{Resumo}

O presente trabalho busca descrever o cotidiano escolar de alunos surdos em escolas da rede básica de ensino do estado do Rio de Janeiro. Observou-se como a Língua Portuguesa (LP) é ministrada a esses alunos e como as relações entre escola, alunos e familiares funcionam. As observações foram registradas em diários de campo, visando estudos futuros sobre elaboração de material de LP como segunda língua e de capacitação de profissionais da área.

\begin{abstract}
The present study seeks to describe the school routine of deaf students from two elementary schools in the state of Rio de Janeiro. It was observed how Portuguese is taught to those students and how the relationships between school, students and families work. The observations were registered in field diaries aiming further studies on material design of Portuguese as a second language and also on professional training.
\end{abstract}

\section{1) Introdução}

Com a lei $n^{\circ} 10.436 / 2002$, que legitima a Língua Brasileira de Sinais (LIBRAS), juntamente com o decreto $\mathrm{n}^{\circ} 5626 / 2005$, que garante aos alunos surdos o acesso a salas de aula bilíngues, fazem-se necessárias mudanças no cotidiano escolar da rede básica de ensino. Para que as escolas possam estar de acordo com as novas recomendações, repensou-se não apenas a grade curricular para atender a demanda dos alunos surdos a serem incluídos, mas, também, estratégias que pudessem facilitar o processo de ensinoaprendizagem do aluno surdo, desde a capacitação do docente à elaboração de recursos didáticos para os alunos. Contudo, ainda se é questionado como, de fato, esse processo de readaptação escolar se reflete em sala de aula. 
Para atender às novas diretrizes, torna-se fundamental a criação de um espaço escolar bilíngue, ou seja, um espaço em que a LIBRAS seja entendida como a primeira língua (L1) do surdo e seu principal meio de comunicação, sendo a Língua Portuguesa (LP) na modalidade escrita sua segunda língua (L2). No entanto, a implementação de espaços como esses tende a ser um processo complicado, em virtude dos investimentos necessários, como a capacitação do professor para atuar com alunos surdos, a presença de um intérprete e recursos visuais que auxiliem esse aluno. Dessa forma, como Leite e Cardoso (2009) indicam, ainda "há falhas na atual política oficial de inclusão no tocante a inclusão escolar de surdos" (LEITE \& CARDOSO 2009, p. 3435). Deve-se ressaltar que o reconhecimento da LIBRAS como língua legítima não exclui o fato de a LP ser a língua oficial brasileira, o que implica que o surdo precisa passar pelo letramento adequado dessa língua, cuja modalidade oral-auditiva difere da característica espaçovisual de sua L1. Assim sendo, é essencial que as escolas que recebem alunos surdos possuam estratégias diferenciadas que possam servir de agentes facilitadores de ensino, evitando, por exemplo, que o surdo seja excluído de um determinado tópico ou que ele tenha sua avaliação prejudicada em virtude de não compreender certos aspectos do conteúdo por estes estarem ligados, de alguma forma, a aspectos orais da LP. Dito isto, essas falhas acabam por reafirmar a importância do bilinguismo em todas as esferas escolares para que, desse modo, o aluno surdo tenha meios de se desenvolver linguisticamente. Com salas de aula bilíngues, a LP pode ser lecionada através da LIBRAS, o que possibilita que o aluno encontre pontos de apoio em sua L1 que o ajudarão a compreender a L2 de forma mais facilitada, permitindo que o aluno faça inferências e relação ao conhecimento de mundo que já possui.

Com isso, o presente trabalho busca verificar como a LP está sendo desenvolvida nas escolas da rede básica de ensino do estado do Rio de Janeiro. Através de observação do ambiente escolar em que o surdo está inserido e das metodologias empregadas no ensino da LP modalidade escrita, espera-se ter elementos de análise para futuras pesquisas pertinentes à elaboração de materiais didáticos para alunos surdos e de estratégias de capacitação de profissionais da área.

De forma a estruturar as informações coletadas nas instituições de ensino, fez-se uso de diários de campo, que são os registros das observações das experiências vivenciadas ao longo de visitações à escolas que possuem atendimento a alunos surdos. Tais registros foram elencados em cinco categorias, a saber:

(1) Estrutura física das escolas;

(2) Relação das escolas com a comunidade;

(3) Aspectos do corpo discente e docente;

(4) Material didático utilizado; (5) Sistema de avaliação utilizado.

As observações foram realizadas em duas escolas: o Instituto Nacional de Educação de Surdos; e a Escola Municipal Santa Luzia. 


\section{2) Breve levantamento histórico das escolas visitadas}

De forma a ser apresentado um panorama geral das duas instituições visitadas, seguem suas descrições.

\section{1) Escola Municipal Santa Luzia}

Localizada no bairro Parque Equitativa, no município de Duque de Caxias, no estado do Rio de Janeiro, a Escola Municipal Santa Luzia (EMSL) apresenta um atendimento diferenciado aos alunos surdos da rede básica de ensino, apesar de não ser caracterizada como uma escola bilíngue. A escola oferece turmas do Ensino Fundamental $\left(1^{\circ}\right.$ e $2^{\circ}$ segmentos), Educação Especial e Educação de Jovens e Adultos (Supletivo).

Fundada inicialmente em 1959 como Escola Paroquial Santa Luzia, foi municipalizada em 1963. Para atender às demandas da comunidade do entorno da escola, em 1981 iniciou-se o atendimento de alunos surdos e com comprometimentos cognitivos. Atualmente, a escola possui uma grade curricular diferenciada, com inclusão da LIBRAS como disciplina obrigatória em todas as séries. Além disso, a escola possui atendimento especializado aos surdos nas fases iniciais de ensino, para que estes possam, então, ser incluídos em turmas mistas, com alunos ouvintes. A escola é uma das precursoras no atendimento ao aluno surdo na região, contando, também, com curso de LIBRAS para professores, funcionários e responsáveis.

\section{2) Instituto Nacional de Educação de Surdos (INES)}

O INES é uma instituição federal de ensino que atende alunos surdos da Educação Infantil ao Ensino Médio. Fundado em 1856, está localizado no município do Rio de Janeiro, no bairro das Laranjeiras. Por ter sido a primeira instituição escolar voltada para a área da surdez, o INES integra a parte histórica que constitui a luta da comunidade surda pela afirmação da LIBRAS e de sua identidade.

O Instituto possui algumas divisões, dentre elas está o Colégio de Aplicação (CAp/INES), que abrange todo o ensino básico, desde a Educação Precoce (recémnascidos a 3 anos de idade) ao Ensino Médio. Atualmente, são atendidos cerca de 500 alunos surdos. O INES, além de contar com o CAp/INES, ainda oferece outros serviços à comunidade, como acompanhamento com fonoaudiólogos, orientação familiar e profissional, curso de LIBRAS aberto a comunidade, seminários e congressos sobre a área e ministra, também, cursos de graduação e pós-graduação (DESU/INES). 


\title{
3) Estrutura física das escolas
}

Iniciamos esta seção com um questionamento: qual escola seria a mais adequada ao aluno surdo?

\begin{abstract}
A maioria dos surdos (mas não todos, é claro) declara sua preferência pelas escolas específicas: imaginam o benefício que poderiam usufruir de escolas nas quais a sua cultura e a sua língua natural fossem prioritariamente disponibilizadas, nas quais a língua de sinais fosse a língua de instrução, escolas nas quais todas as pessoas usassem a língua de sinais (ainda que fossem ouvintes) e os modelos perseguidos não fossem os "modelos ouvintes", escolas que tivessem professores surdos e trabalhadores surdos de modo geral. (SÁ, 2011. p.21)
\end{abstract}

A partir da reflexão trazida por Sá (2011, p. 21), deve-se ressaltar a importância de se pensar em escolas para surdos que possuam estrutura adequada para atender às suas especificidades linguísticas. Tendo em vista que a primeira língua do surdo, a LIBRAS, é espaço-visual, contar com uma escola que ofereça aparatos visuais que possam ser trabalhados dentro e fora de sala de aula torna-se essencial para facilitar o processo de aprendizado do aluno. É importante ressaltar que esses recursos não precisam ser, exclusivamente, tecnológicos. Há diversas possibilidades de se utilizar imagens em sala de aula, seja através de murais, revistas, jornais. Uma estrutura escolar adequada é importante não apenas para que o conteúdo seja melhor assimilado, mas também para que o aluno surdo possa adquirir autonomia dentro das dependências da escola.

Sob essa perspectiva, observou-se o espaço o que o aluno surdo está inserido, bem como os recursos disponíveis nas escolas. Na Escola Municipal Santa Luzia, pôdese observar uma estrutura física organizada, com salas de leitura e de informática, além de salas de aula para cada turma. Os corredores da escola possuem alguns murais informativos e, em alguns deles, é possível encontrar informações em LIBRAS, registros com desenhos representando alguns sinais ou com o uso de datilologia ${ }^{1}$, assim como a divulgação dos projetos desenvolvidos em sala de aula com os alunos surdos. Os murais são elaborados pela equipe da escola, mas também há a contribuição dos alunos, visto que em alguns murais encontravam-se trabalhos de alunos realizados em sala de aula.

A EMSL atende tanto alunos surdos como ouvintes. No turno da manhã, os alunos surdos do primeiro segmento do Ensino Fundamental participam de aulas especializadas, em que há o contato com a cultura surda. Há, no máximo, 12 alunos por turma e as salas, em geral, dispõem de quadro branco, elementos visuais alocados na parede em forma de mural, manuário em LIBRAS e outros recursos que possam servir como apoio ao aprendizado do aluno. As salas de aula em que os alunos estão incluídos, a partir do

\footnotetext{
${ }^{1}$ Datilologia é o alfabeto manual em LIBRAS, usada quando se há a necessidade de "soletrar" um termo, como nomes de pessoas, ruas.
} 
segundo segmento do Ensino Fundamental, ou seja, em que há alunos surdos e ouvintes, são maiores em virtude de comportarem um número maior de alunos.

Essas estratégias de organização da escola auxiliam os discentes surdos a tornarem-se autônomos no desempenho de atividades escolares cotidianas e, ainda, permitem com que os alunos sintam-se parte da escola, já que há elementos de sua cultura e de sua língua pelos corredores e salas de aula. Características como essas também foram evidenciadas no Instituto Nacional de Educação de Surdos. No entanto, as proporções dessa organização estrutural são mais abrangentes, em virtude de o INES ser uma instituição federal voltada para o surdo desde sua fundação. Sua estrutura, por exemplo, conta não apenas com salas de aulas, mas com espaços de acompanhamento do surdo dentro e fora do ambiente escolar. A instituição também recebe alunos de todas as localidades do município do Rio de Janeiro, o que indica que há uma diversidade de alunos maior no que a observada na Escola Municipal Santa Luzia. O Instituto possui alguns prédios anexos, os quais oferecem tratamento com fonoaudiólogos, espaços para os responsáveis, acervo histórico, além de espaço destinado à Graduação e PósGraduação.

No prédio principal, há salas de aula que possuem recursos tecnológicos como televisão e computador para reprodução de material visual durante as aulas. Nas salas, as carteiras e armários possuem a descrição em LP. Os pisos das salas e dos corredores são de madeira, o que permite ao aluno sentir a vibração dos demais alunos e funcionários que circulam nas dependências da escola. Há, também, murais e televisões pelos corredores, com informações em LP e LIBRAS. Por ser uma escola voltada exclusivamente para o ensino de alunos surdos em âmbito federal, é possível perceber maiores investimentos estruturais que possibilitem aos alunos maior contato com a cultura surda nas dependências da instituição.

\section{4) Relação das escolas com a comunidade}

Um dos grandes empecilhos ao desenvolvimento do aluno surdo é, dentre outros aspectos, a falta de diálogo entre escola e a comunidade que a integra. Mesmo havendo atividades específicas dentro de sala de aula, muitos alunos não conseguem desenvolver suas habilidades plenamente por não haver possibilidades de comunicação fora de sala de aula, visto que muitos pais e responsáveis desconhecem a língua de sinais. Dessa forma, o modo como a LIBRAS e a Língua Portuguesa serão trabalhadas dentro e fora de sala de aula refletirá no processo de letramento dos alunos. Sob esse prisma, a escola deveria possibilitar que o surdo tenha acesso tanto à LIBRAS, sendo esta trabalhada como sua primeira língua, quanto à LP modalidade escrita, a qual deve ser entendida como a segunda língua do surdo, fazendo com o que o aluno possa entrar em contato com aspectos do mundo ouvinte e do mundo surdo (PEREIRA, 2014, p. 143-157). 
Para que isso seja possível, as escolas precisam fornecer ferramentas para que haja essa real interação. Durante a visitação da EMSL, pôde-se perceber que escola e comunidade dialogam. A escola oferece aos familiares cursos gratuitos de LIBRAS e os orientam a buscar auxílio médico especializado, quando necessário. Os cursos de língua de sinais são oferecidos aos pais, responsáveis e, também, aos funcionários da escola. Tais ferramentas ajudam a minimizar a distância entre surdo e ouvinte, ao passo em que a cultura e língua de ambos os lados são colocados em voga. Os alunos, assim, conseguem interagir em LIBRAS com seus professores e familiares, ampliando as possibilidades do aluno de desenvolver o conhecimento que foi aprendido em sala de aula.

No INES, essa interação entre escola e comunidade também é possível. Contudo, a abrangência de tais medidas acaba por ir além do núcleo familiar dos alunos. O Instituto oferece cursos de LIBRAS não apenas aos pais e responsáveis, mas também à comunidade externa, corroborando para a divulgação da língua de sinais e da cultura surda. Desse modo, ao ampliar as possibilidades de comunicação do aluno surdo, este pode expandir seu conhecimento de mundo, o que o permitirá assimilar a LP mais facilmente (PEREIRA, 2014, p. 143-157).

É importante ressaltar a importância de ambas as instituições observadas oferecerem cursos de LIBRAS à comunidade. Em conversas com alguns profissionais de ensino nas escolas observados, foi relatado que muitos alunos chegam às salas de aula sem conhecimento algum de LIBRAS ou de LP, ou seja, alguns alunos iniciam sua vida escolar sem língua. Isso se deve ao fato de que muitos pais e responsáveis desconhecem a língua de sinais ou aspectos da comunidade surda, o que implica que a comunicação dentro de casa é feita através de gestos de acordo com a necessidade imposta pelas situações cotidianas. Ao possibilitar que a família também se integre ao contexto escolar, o aluno surdo passa a ter outras condições de se comunicar dentro e fora de sala de aula, visto que seus pais agora terão condições se comunicar adequadamente com seus filhos. De fato, o aluno disporá de novas ferramentas que o auxiliarão em seu desenvolvimento escolar e como indivíduo dentro de uma sociedade.

\section{5) Aspectos do corpo discente e docente}

O papel do educador é fundamental para que o aluno desenvolva-se plenamente. Esse deve criar ambientes e situações que possam contribuir para o desenvolvimento dos alunos. Ao entrar em contato com diferentes contextos escolares, foi possível perceber algumas peculiaridades no que diz respeito à relação professor - aluno surdo. Os relatos de alguns professores indicam que há uma dependência maior desse aluno em relação ao professor do que quando comparado essa mesma relação com alunos ouvintes - talvez por esse profissional ser um dos poucos a interagir com surdos em Libras.

Contudo, esse ponto merece ser observado com mais atenção. Skliar (1999, p.7), por exemplo, sugere que há "uma forma particular e específica, de colonização dos ouvintes sobre os surdos", ou seja, o educador pode acabar por sofrer influência de um círculo de "baixas expectativas pedagógicas", levando-o a acreditar que o aluno tenha 
uma limitação natural para aprender. Com isso, faz-se necessário que o professor receba devido direcionamento quanto às especificidades do aluno surdo, tomando conhecimento de suas diferenças linguísticas e de características de sua cultura, para evitar uma visão errônea do sujeito surdo.

Com isso, o professor precisa compreender que, por ser a LP a segunda língua para o surdo, sua produção pode ser, inicialmente, truncada e de difícil entendimento, devido à interferência de elementos de sua L1, como a ausência de conectivos ou flexão verbal, por exemplo. Como Pereira (2014, p. 143-157) afirma, o professor, dessa forma, precisa repensar suas metodologias, criando parcerias com os alunos, respeitando suas características linguísticas e levando-o a desenvolver as habilidades requeridas para aquela atividade em questão. Essas medidas tornam-se necessárias para que não se tenha a visão equivocada de que o aluno surdo não consegue aprender a LP, visão que, por muito tempo, foi difundida.

Em conversa com professores das escolas visitadas, alguns mencionaram a dificuldade que alguns alunos surdos apresentam em aprender a LP. Na EMSL, no entanto, para reverter esse quadro, a sala de recursos acabou se tornando um aliado do professor, pois é um espaço em que há acesso a livros, filmes e imagens, o que permite a interação da LIBRAS e da LP modalidade escrita. Na escola de Duque de Caxias, na parte da manhã, funcionam as classes do primeiro segmento do Ensino Fundamental, com turmas exclusivas para alunos surdos. Nessas salas, há a participação do professor regente da turma e, também, de assistentes educacionais. Importante ressaltar que os professores dessas turmas possuem certo nível de fluência em LIBRAS e os assistentes presentes são surdos. Assim sendo, cria-se um espaço propício ao desenvolvimento dos alunos, que interagem com as duas línguas, a saber, a LIBRAS e a LP modalidade escrita. O professor, então, busca recursos que possibilite a criação de um ambiente bilíngue de ensino, para que, futuramente, esses alunos possam ser inseridos em salas de aula mistas. De acordo com a direção da escola, os professores recebem orientações específicas para essas aulas, além de acompanhamento regular e educação continuada.

Os alunos que foram observados na EMSL possuem diferentes níveis de surdez: alguns possuem prótese coclear e estão sendo oralizados. No entanto, há alunos que chegam à escola sem língua ou com nível bem elementar de LIBRAS, segundo relato de professores. Como já foi dito, os alunos participam de aulas com o professor regente, que é bilíngue, e também tem contato com assistentes de ensino, que são surdos e auxiliam o professor no desenvolvimento da aula. A partir do segundo segmento do Ensino Fundamental, os alunos passam a frequentar turmas mistas, em que há alunos surdos e ouvintes. Conforme relato dos professores, os alunos surdos são bem recebidos pelos alunos ouvintes e, estes, em geral, tentam interagir utilizando a LIBRAS que tem contato em sala de aula, visto que esta é uma disciplina obrigatória na grade curricular da escola. Nas classes de inclusão, a dinâmica de sala de aula se modifica, pois há a presença de um intérprete. 
Em contrapartida a esse cenário em que a escola busca se adequar à demanda de alunos surdos, o INES apresenta classes com uma metodologia bilíngue desde os anos iniciais até a conclusão do ensino médio. Suas turmas são compostas apenas de alunos surdos, os quais também possuem graus distintos de surdez. Há, em sala de aula, toda uma organização que propicia a interação da LIBRAS e da LP. Nem todos os professores são proficientes em LIBRAS, mas todos buscam estratégias que possam auxiliar o aluno surdo. A presença de intérpretes em sala, somente realizada quando solicitada pelo professor, pode facilitar o processo de aprendizagem quando o professor regente não domina a língua de sinais.

Contudo, apesar de ser uma escola voltada exclusivamente para alunos surdos, foi possível observar que ainda há dificuldades no que diz respeito à interação entre alunos e demais funcionários da escola. Apesar de tais barreiras linguísticas, os alunos surdos mostraram-se ã vontade em seu ambiente escolar, grande parte em virtude do intenso trabalho dentro e fora de sala de aula de reafirmação da cultura e da identidade surda. Com um ambiente em que as características da comunidade surda são evidenciadas, tirando o foco clínico da surdez, os alunos sentem-se, de fato, como sujeitos atuantes daquele ambiente escolar.

\section{6) Material didático utilizado}

Para que o professor consiga atingir seus objetivos, ele precisa contar com recursos diversos que possam auxiliá-lo no andamento das aulas. Dito isto, ressalta-se a importância do material didático (MD). Este pode ser entendido como um instrumento utilizado em sala de aula capaz de agrupar meios e recursos que auxiliem o professor a organizar o conteúdo a ser passado, como SANTOS (2012, p. 4) afirma. Logo, esse MD deve agir como um facilitador no processo de ensino-aprendizagem do aluno. Levandose em consideração as especificidades linguísticas do aluno surdo, os materiais voltados para o ensino de LP como segunda língua para esse alunado devem apresentar recursos visuais que facilitem a aprendizagem do conteúdo. Tal aspecto visual deve dialogar com o assunto trabalhado e a cultura do surdo, permitindo que o discente tenha meios de pensar criticamente e refletir sobre o conteúdo em questão.

Entretanto, os docentes que trabalham com os surdos não conseguem encontrar MD suficientes, pois poucos são publicados e, mesmo assim, nem todos são disponibilizados para as escolas. Essa situação pode ser constatada em outros estudos:

[...] no caso de professores que atuam com o ensino de alunos surdos há uma lacuna, pois não dispomos de um volume representativo de materiais para o ensino das disciplinas da escola, que contemplem a educação bilíngue dos surdos. Sendo assim, o professor de cada disciplina fica responsável por pesquisar ou elaborar atividades e materiais didáticos para o surdo. (SANTOS, 2012, p. 4-5) 
Em seu texto, TEIXEIRA (2015, p. 90-91) faz um pequeno levantamento de materiais voltados para o ensino de Português para surdos. Esses materiais podem ser divididos em 4 grupos:

- Livros voltados para educadores como Ensino de Língua Portuguesa para Surdos: caminhos para a prática pedagógica, volumes 1 e 2 (SALLES; FAULSTICH; CARVALHO; RAMOS. 200 e Ideias para Ensinar Português para Alunos Surdos (QUADROS; SCHMIEDT, 2006);

- Livros voltados para orientações curriculares como Orientações Curriculares: Proposição de Expectativas de Aprendizagem- Língua Portuguesa para Pessoa Surda (SÃO PAULO, 2008), o Projeto Toda Força ao $1^{\circ}$ ano-contemplando as especificidades dos alunos surdos (SÃO PAULO, 2007) e Orientações Curriculares- Proposições de Expectativas de Aprendizagem- Língua Brasileira de Sinais (SÃO PAULO, 2008);

- Livros voltados para o público discente da A Coleção Pitanguá (2007);

- Manual de atividades chamado Português... eu quero ler e escrever (ALBRES, 2010).

Voltando aos materiais utilizados nas escolas, observou-se que, na EMSL, os professores, em sua maioria, não se apoiam em um livro didático específico, devido ao fato da escassez de recursos no que diz respeito a materiais voltados para a comunidade surda. A escola recebe livros didáticos, disponibilizado pelo Programa Nacional do Livro Didático (PNLD), destinados aos alunos da rede pública de ensino. No entanto, esse material não possui recursos que atendam às necessidades dos alunos surdos. Para suprir tal ausência, os professores desenvolvem materiais que sejam apropriados às especificidades do alunado surdo, buscando inserir aspectos da cultura surda. Sobretudo, utilizam-se de recursos visuais de forma a tornar a apreensão do conteúdo mais adequada, ajudando, assim, o processo de ensino-aprendizagem do aluno.

Deve-se destacar ainda que o governo estadual (RJ) exige que alguns materiais sejam obrigatórios em sala de aula, como o "cantinho da leitura", uma exigência da Secretaria de Estado de Educação do Rio de Janeiro (SEEDUC) que orienta a criação de espaços específicos para a utilização de material enviado exclusivamente para essa finalidade. $\mathrm{O}$ material enviado à escola para uso dos alunos do primeiro segmento do Ensino Fundamental, por sua vez, acaba sendo adaptado de forma a ser possível de integrar o conteúdo à experiência linguística desses alunos. Já no segundo segmento do Ensino Fundamental, de acordo com os relatos de professores, a escola não recebe nenhum tipo de material didático específico para surdos. Esses discentes utilizam o mesmo material que ouvintes, em que a LP é abordada como primeira língua. Apesar 
dessa problemática, há a elaboração, por parte do corpo docente, de materiais extras, com recursos visuais que possam facilitar o processo de ensino-aprendizagem do aluno surdo. Em algumas salas de aula visitadas, foi possível constatar alguns desses recursos, os quais estavam dispostos em murais e/ou paredes. O conteúdo desse material incluía imagens que ilustravam o alfabeto, dias da semana e outras palavras e expressões que os alunos estavam aprendendo.

Ao visitar o INES, observou-se que a instituição, assim como a EMSL, recebe material didático fornecido pelo governo federal, distribuído PNLD (Plano Nacional do Livro Didático). A instituição recebe, também, os livros excedentes de outras escolas que atendem somente alunos ouvintes. Observa-se que essa prática também é comum em outras escolas destinadas a alunos surdos, como evidencia LEITE \& CARDOSO (2009, p. 3436, 3437) que fala do Centro Estadual de Atendimento e Apoio ao Deficiente Auditivo (CEAADA), localizado no estado do Mato Grosso, que dependia de doações desses materiais. Contudo, os livros enviados pelo governo e por outras instituições não possuem os recursos especializados para alunos surdos, além de o material não fazer referência à sua cultura ou à sua identidade, excluíndo qualquer tipo de manifestação cultural do aluno surdo.

Apesar de ocorrer essa situação, as salas de aula dispõem de recursos tecnológicos que são utilizados para atender às necessidades do aluno surdo e auxiliam na aula. Com esses recursos, o professor consegue dinamizar a aula, criando meios de atender às especificidades linguísticas dos alunos. Observou-se, também, que os professores da instituição tendem a elaborar MDs que possam trabalhar não só com o conteúdo programático, mas também com a conscientização cultural e de identidade do aluno, buscando elementos na LIBRAS que possam auxiliar o desenvolvimento da LP modalidade escrita. É importante destacar que, em geral, os professores de Língua Portuguesa compartilham os materiais elaborados por eles, de forma a ampliar a disponibilidade de recursos que podem ser reutilizados em outros momentos.

\section{7) Avaliação utilizada}

Como Fernandes (2007, p. 16) aponta, a avaliação para alunos surdos deve ser diferenciada da avaliação feita para ouvintes. Os critérios utilizados em cada avaliação devem ter alvos específicos, devendo-se evitar a comparação entre a produção do aluno ouvinte e a produção do aluno surdo. O professor deve avaliar o aluno surdo a partir de seu desenvolvimento nos mais variados níveis da escrita, podendo até mostrar uma comparação entre as demais produções do aluno "nos diferentes estágios que percorre, apresentando características decorrentes da interferência da LIBRAS e da sobreposição das regras da nova língua que está aprendendo" (FERNANDES, 2007, p.16).

$\mathrm{O}$ processo de aprendizagem do aluno e uma boa avaliação estão ligados à necessidade da adequação de metodologias voltadas para especificidades de ensino que levem os discentes surdos a utilizarem a LP como segunda língua. Dessa maneira, a avaliação dos alunos surdos deve valorizar o conteúdo trabalhado em sala aula de forma 
que seu desenvolvimento seja refletido em sua produção escrita. Assim, o professor passará a buscar critérios de avaliação que possam reconhecer e respeitar as diferenças linguísticas do aluno surdo em relação a essa língua.

Conforme observado na EMSL, os professores do turno da manhã, em que há atendimento específico para alunos surdos, elaboram avaliações de acordo com o conteúdo apresentado em sala de aula, partindo do pressuposto que "o acesso à língua portuguesa, como segunda língua, possibilitará a ampliação de suas relações sociais e a

apropriação de elementos da cultura nacional, comuns a todos os brasileiros" (FERNANDES 2007, p.3). Assim, as avaliações são provas ou trabalhos feitos durante alguns dias destinados para esses tipos de atividades. Em relação às turmas mistas, com ouvintes e surdos, poucas informações foram divulgadas sobre o método de avaliação utilizado, mas uma das professoras mencionou que para algumas turmas, buscou-se elaborar um método alternativo, com avaliações em vídeo. O objetivo era o de realizar provas audiovisuais para os alunos. Entretanto, devido à falta de recursos, não foi possível dar continuidade a essa forma de avaliação. Mas espera-se que, futuramente, novas avaliações nessa modalidade sejam realizadas. Esse tipo de avaliação passa a ser muito importante, pois leva em conta aspectos visuais através da tecnologia como forma de incentivar os alunos no processo de ensino-aprendizagem.

Apesar da iniciativa com esse tipo de avaliação, o que é feito na escola pela maioria dos professores é abordar ou discutir previamente o conteúdo/texto que será cobrado com seus alunos para que, no dia da prova, todos estejam cientes do assunto que será abordado. Além disso, é muito importante que haja também imagens para auxiliálos, embora alguns professores não as utilizem. No dia da avaliação, o intérprete acompanha o aluno, auxiliando-o no entendimento dos enunciados.

Já no INES, pouco foi informado quanto às avaliações feitas pelos professores do instituto. Observou-se que os alunos são avaliados através de provas e trabalhos elaborados pelos próprios docentes. Como critérios de avaliação, os professores buscam analisar o interesse despertado pelos alunos em relação ao conteúdo, a sua adequação deste às necessidades dos aprendizes e à sua cultura, resultando na capacidade de avaliação do desenvolvimento do aluno e a integração com o que apresentado em sala de aula, de forma que:

(...) fica claro que os surdos podem ser considerados bilíngues ao dominarem duas línguas legitimamente brasileiras, posto que ambas expressam valores, crenças e modos de percepção da realidade de pessoas que compartilham elementos culturais nacionais. Ocorre que uma das línguas - o português - é a língua oficial e majoritária - enquanto que a outra - a Libras - é uma língua minoritária, utilizada por um grupo restrito de pessoas. (FERNANDES, 2007, p.2) 


\section{8) Considerações finais}

As observações do cotidiano escolar da Escola Municipal Santa Luzia e do Instituto Nacional de Educação de Surdos evidenciaram a necessidade de se repensar as estratégias metodológicas destinadas à educação de surdos. Apesar de haver leis e decretos que regulamentem a LIBRAS e que orientem às escolas a receberem alunos surdos, ainda há escassez em recursos e uma defasagem na capacitação de profissionais da área.

Mesmo com o envio de livros didáticos às escolas, estes não se adequam à realidade do surdo. Os professores que recebem orientações fragmentadas quanto ao como lidar com alunos surdos, precisam se reinventar e buscar novos recursos diariamente para que o surdo tenha a possibilidade de acessar o conteúdo previsto para a aula.

Contudo, é preciso ressaltar que o cenário relatado neste trabalho é resultante de escolas que possuem, em algum grau, um atendimento diferenciado a alunos surdos. Porém, é preciso salientar que essa não é a realidade em todas as escolas do estado do Rio de Janeiro. Se mesmo em escolas que possuem um diferencial curricular que inclui o surdo em seu contexto há grandes dificuldades de se criar um espaço bilíngue, em que a Língua Portuguesa modalidade escrita seja a segunda língua do surdo, o que se esperar de escolas que dispõem de menos recursos e de um corpo docente sem preparo adequado para lidar com alunos surdos e ouvintes em um mesmo ambiente de sala de aula?

As experiências vivenciadas nessas duas instituições de ensino corroboram com a necessidade de se refletir sobre como se dará o processo de ensino-aprendizagem do surdo. Há a urgência de se debater novas estratégias de ensino que perpassem a necessidade de capacitar adequadamente os profissionais que estarão em sala de aula com esses alunos e na reformulação do material didático que é enviado às escolas, visto que este não se adequa às necessidades do aluno. Estratégias precisam ser criadas para que o surdo possa ter acesso, de fato, a um espaço bilíngue, em que ele possa dispor de todas as condições para se desenvolver linguisticamente, sem ter de anular sua identidade surda.

\section{Referências}

BRASIL. Lei n ${ }^{\circ} 10.436$, de 24 de abril de 2002. Dispõe sobre a Língua Brasileira de Sinais. Diário Oficial [da República Federativa do Brasil], Brasília, DF, n. 79, p. 23, 25 abril 2002.

Decreto $n^{\circ} 5.626$, de 22 de dezembro de 2005. Regulamenta a Lei $n^{\circ} 10.436$, de 24 de abril de 2002, que dispõe sobre a Língua Brasileira de Sinais - Libras, e o art. 18 da Lei $\mathrm{n}^{\circ} 10.098$, de 19 de dezembro de 2000. Diário Oficial [da República Federativa do Brasil], Brasília, DF, p. 28, 23 de dezembro de 2005.

FERNANDES, Sueli. Avaliação em língua portuguesa para alunos surdos: algumas considerações. In: Secretaria de Estado da Educação. Grupos de estudos por área. Curitiba, 2007. Disponível em: http://www.diadiaeducacao.pr.gov.br/portals/portal/institucional/dee/deesurdez.php 
LEITE, J. G.; CARDOSO. J. Inclusão Escolar de Surdos: Uma análise de livros de alfabetização. In. Anais do IX Congresso Nacional de Educação - EDUCERE.

Curitiba: Champagnat, 2009, p.1-13. Disponível em: http://www.pucpr.br/eventos/educere/educere2009/anais/pdf/3 250 1545.pdf.

PEREIRA, M. C. C. O ensino de português como segunda língua para alunos surdos: princípios teóricos e metodológicos. In: Educar em Revista. Editora UFPR, Curitiba. Edição Especial, n.2, 2014, p. 143-157.

SÁ, N. de (org). Escolas e Classes de Surdos: opção político-pedagógica legítima. In: Surdos: qual escola? Manaus: Editora Valer e Edua, 2011.

SANTOS, E. R.. O ensino de língua portuguesa para surdos: uma análise de materiais didáticos. In: II Simpósio Internacional de Ensino de Língua Portuguesa, 2012, Uberlândia. Anais do SIELP, 2012. v. 2., p. 4-6.

SKLIAR, C. Localização política da educação bilingue para surdos. In: SKLIAR, C. (org) Atualidade da educação bilingue para surdos. Porto Alegre: Mediação, 1999. p. $7-14$

TEIXEIRA, V. G. Encontros e desencontros: reflexões sobre a prática pedagógica no ensino de português como L2 para surdos à luz da Teoria dos Sistemas Complexos. 2015. 198f. Dissertação [mestrado]. Universidade do Estado do Rio de Janeiro, Programa de Pós-Graduação em Letras. Rio de Janeiro, 2015. 